\title{
Noise Pollution in Mosul Medical City Center Teaching Hospitals
}

\author{
Humam G. Al-Zubeer ${ }^{a}$, Asma A. Al-Jawadi ${ }^{a}$, Miss Raghad A. Al-Joomard ${ }^{\text {b }}$ \\ From the ${ }^{\mathrm{a} D e p a r t m e n t}$ of Community Medicine, College of Medicine, University of Mosul, ${ }^{\mathrm{b}}$ Research assistant, Nineveh College \\ of Medicine, University of Mosul. \\ Correspondence: Humam G. Al-Zubeer. Lecturer, Department of Community Medicine, College of Medicine, University of \\ Mosul, Mosul, Iraq. Email: humamalzubeer@yahoo.com. \\ (Ann Coll Med Mosul 2013; 39 (1): 32-37). \\ Received: $2^{\text {nd }}$ Feb. 2012; Accepted: $2^{\text {nd }}$ Oct. 2012.
}

\section{ABSTRACT}

Context: High levels of noise in hospitals may interfere with patient care services, the doctor-patient relationship and medical education activities.

Aim: To measure the noise level and to determine the time-place patterns at Mosul Medical City Center Teaching Hospitals.

Materials and methods: Sound levels of different places inside the stated hospitals were recorded, using a Digital Sound Level Meter. A total of 80 readings were taken at different locations of hospitals. The time for each measurement was 5 minutes, repeated for three times in each location, and then the average reading was recorded. Three noise parameters were recorded in every measurement (in dBA): equivalent noise level (Leq), maximum noise level $\left(L_{\max }\right)$ and minimum noise level $\left(L_{\text {min }}\right)$. Neither the staff nor the patients in the four institutions were aware of the recordings.

Indoor noise levels on weekdays (Saturday through Thursday) were compared to noise levels on weekends (Friday). Outdoor noise levels were measured near each hospital facet, too. Time-patterns of noise pollution were established by recordings at 08:00 a.m., 09:00 a.m., 11:00 a.m., and 02:00 p.m.

Results: The mean equivalent sound level was $93.44 \pm 6.55 \mathrm{dBA}$, including hospitals facet. The maximum equivalent sound level was observed in the casualty department $(97.80 \pm 2.91 \mathrm{dBA})$ and the minimum equivalent sound level was in Ibn-Sena General Teaching Hospital $(89.16 \pm 6.83 \mathrm{dBA})(p=0.001)$. During morning hours, the mean equivalent noise level (94.35 dBA) was higher than the afternoon level (90.14 dBA) $(p=0.037)$. The mean equivalent noise levels were higher on the weekdays $(94.05 \mathrm{dBA})$ than on the weekend $(88.57 \mathrm{dBA})(\mathrm{p}=0.002)$.

Conclusion: The noise pollution in Mosul Medical City center greatly exceeded the WHO guideline level for hospitals. This study highlights the need for noise monitoring and control measures inside hospital areas.

Keywords: Noise pollution, hospitals, patterns.

$$
\text { التلوث الضوضائي في المستثفيات التعليمية لمركز مدينة الطب في الموصل }
$$

مقدمة: المستوى العالي للضوضاء في المستشفيات قد يؤثر على مستوى الخدمات المقدمة للمريض، وعلاقة المريض بالطبيب وكذللك على نشاطات التعليم الطبي. هدف الار اسة: تهدف الدراسة الحالية إلى قياس مستوى الضوضاء وتحديد النمط المكاني و الزماني لها في المستشفيات التعليمية

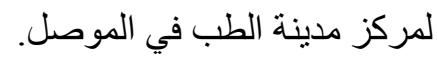

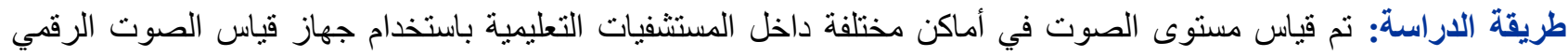
دمigital Sound Level Meter)

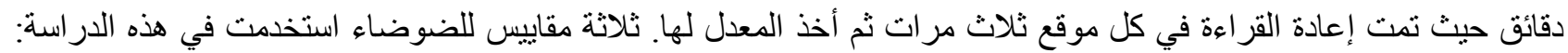

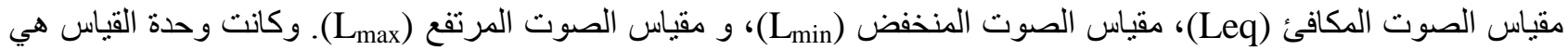

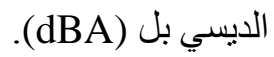




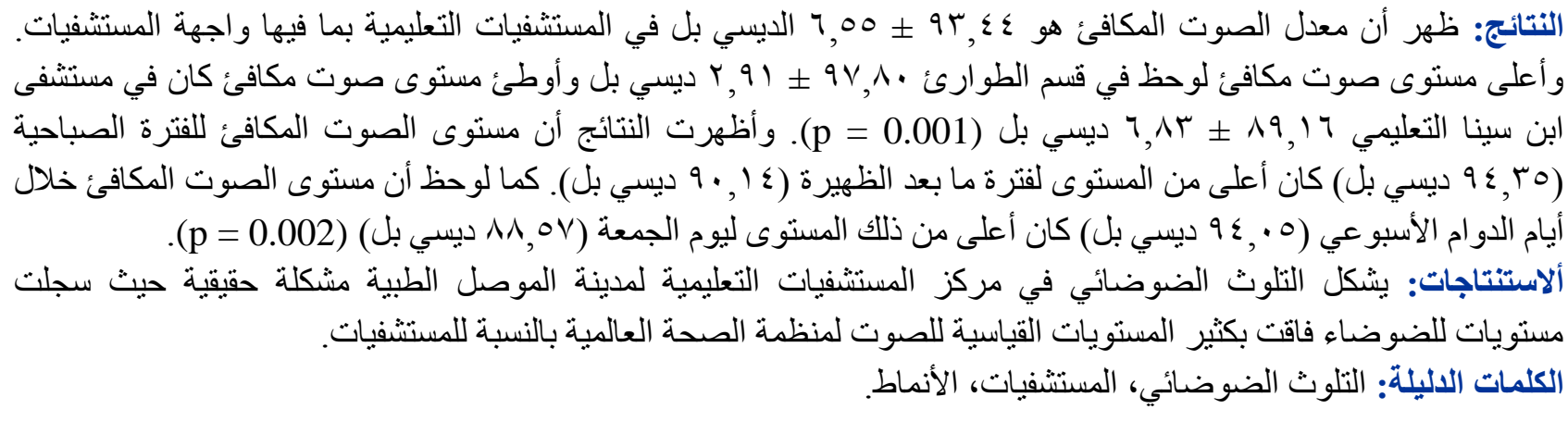

$\mathrm{N}$ oise is a sound that lacks agreeable musical quality, is noticeably unpleasant, is undesired and interferes with one's hearing. Noise pollution is annoying or harmful in an environment ${ }^{(1)}$. Noise exceeding a quiet level of $40-50$ decibel (dBA) is known to cause emotional reactions (annoyance), disturbed sleep, delirium, elevation of blood pressure, tachycardia and is possibly linked to ischemic heart disease, presumably as a result of coronary vasoconstriction ${ }^{(2-5)}$. Exposure to noise has been shown to have a negative impact on work performance ${ }^{(6)}$.

Recent study demonstrated a significant association with sound peaks $>80 \mathrm{dBA}$ and arousals from sleep ${ }^{(7)}$. Moreover, it has been found that patients have sleep fragmentation, detected as transient EEG arousals, when they receive tone bursts during all stages of sleep ${ }^{(8)}$. Sleep deprivation has been demonstrated to affect task performance, general mood, and level of alertness, and can lead to increased daytime fatigue ${ }^{(9)}$. Observational studies have shown that at least one third of sleep-deprived persons have symptoms consistent with "intensive care unit psychosis" syndrome and that patients identify staff noises as the most disturbing ${ }^{(7-9)}$. A threeminute noise at $36 \mathrm{dBA}$ will awaken about half of people in stage 2 sleep, but the noise level must be raised to $83 \mathrm{~dB}$ to awaken half of sleepers in stages 3 and $4{ }^{(3)}$. Older people and women are more vulnerable to the disruptive effects of noise on sleep. Since older people sleep less deeply than younger people, a 70-year-old is about twice as likely to be awakened by sound as a 20 -yearold $^{(3)}$.

Noise has also been implicated as a cause of hearing loss, especially in patients concomitantly receiving ototoxic drugs such as aminoglycosides $^{(1,6)}$. Additionally, noise has been implicated in contributing to critical care nurse burnout ${ }^{(10)}$.

A noise level above $70 \mathrm{dBA}$ is a typical environmental stressor triggering acute and chronic increase in catecholamine levels (epinephrine and norepinephrine) from the adrenal medulla in normal persons, whereas anxious people have especially large increases in plasma and urinary hydroxycorticosteroid levels ${ }^{(11)}$.

A hospital must create a quiet, calm environment for patients by providing a physical setting conductive to recovery and an organizational culture that supports patients and families through the stresses imposed by illness, hospitalization, medical visit, healing and bereavement. To accomplish these, hospital employees must identify internal and external noise factors. Also the hospitals must measure and reduce the noise in patient's room with defined compliance levels ${ }^{(12)}$.

Environmental noise in hospitals has received attention in the medical literature. The Environmental Protection Agency recommends that noise levels in the hospital setting not exceed $45 \mathrm{dBA}$ during the day and $35 \mathrm{dBA}$ at night ${ }^{(13)}$. While the International Noise Council and the World Health Organization has recommended that noise levels in hospital areas should be 35-40 dBA in the daytime and 30-40 dBA in the evening ${ }^{(14-15)}$.

The aim of the present research is to measure noise levels, and to determine its time-and placepatterns in Mosul Medical City Center Teaching Hospitals (Mosul MCCTHs) and Casualty Department (CD) within the mentioned center.

\section{MATERIALS AND METHODS}

Administrative agreement and design: Before starting data collection administrative and ethical agreements were obtained from Nineveh Directorate of Health. To achieve the aim of the 
present study, hospital-based descriptive study design was adopted.

Study settings: The levels of noise measured in the following settings: Al-Jamhory, Al-Batool Maternity and Ibn-Sena General Teaching Hospitals. In addition to the CD. This department is attached to Al-Jamhory Teaching Hospital and located nearby the same hospital.

Method of noise estimation: Noise levels were recorded by the last author using Digital Sound Level meter (SLM) which is a hand hold instrument, (Model 2900 a product of QMEST TECHNOLOGIES (1060 Corporate Center Drive Oconomowoe, WI 53066 NSA 800-245-D779)), in $\mathrm{dBA}$ at different areas of the study settings and at various times. Before each measurement, standardization of the equipment was done. The time for each measurement was 5 minutes, recording was repeated for three times in each location, and then the average reading was recorded. A total of 80 readings were taken in different locations of the study settings. Three noise parameters were recorded in every measurement in dBA: equivalent noise level (Leq), maximum noise level $\left(L_{\max }\right)$ and minimum noise

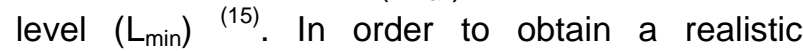
recording of noise levels, neither the staff nor patients in the four institutions were aware of the recordings

In order to find place-pattern of noise pollution, noise levels were recorded in four places of the Mosul MCCTHs. The $1^{\text {st }}$ location was hospital floors: medical, gynecological and/or surgical floors. The $2^{\text {nd }}$ location was consultation units. The $3^{\text {rd }}$ location was intensive care units i.e. coronary care unit (CCU), respiratory care unit (RCU), and surgical intensive care unit (SICU) and finally nurses' stations. In addition to CD rooms: medical and surgical units. In all hospitals areas, noise levels on weekdays (Saturday through Thursday) were compared to noise levels on weekends (Friday). Outdoor noise levels were also measured near each hospital facets.

In order to establish time-patterns of noise pollution, recordings were obtained at 08:00 a.m., 09:00 a.m., 11:00 a.m., and 02:00 p.m.

Outcome measure and statistical analysis: The main outcome measure used was noise level in
dBA. The parameter universally used in the discussion of noise pollution is Leq, the equivalent continuous noise level expressed in $\mathrm{dBA}$, which is the average rate at which energy is received by the human ear during the period monitored. The other variables obtained were $L$ max and $L$ min which are the maximum and minimum noise levels recorded at each place respectively.

Data were tabulated using Minitab - version 13.2 and analyzed using simple descriptive statistics. Independent (unpaired) T- test for two means and analysis of variance for multiple means were used. $\mathrm{P} \leq 0.05$ were considered significant throughout data analysis.

\section{RESULTS}

The mean Leq for all study areas was $93.44 \pm 6.55$ $\mathrm{dBA}$, including hospitals facet. Table 1 shows the mean Leq for individual areas in the MCCTHs and CD rooms. Regarding the average level for each hospital setting, the maximum Leq was observed in the CD $(97.80 \pm 2.91 \mathrm{dBA})$ and the minimum Leq was in the Ibn-Sena General TH $(89.16 \pm 6.83$ $\mathrm{dBA}$ ) with a difference of highly significant value, $p$ $=0.001$. In respect to the different locations, the maximum mean Leq was observed in the hospital facet of Al-Jamhory TH (98.62 $\pm 4.85 \mathrm{dBA})$ and the minimum mean Leq was in the CCU and RCU of Ibn-Sena General TH $(85.46 \pm 4.81 \mathrm{dBA})$.

The minimum noise level $(L \mathrm{~min})$ was recorded in Ibn-Sena General TH (71.88 dBA), while the maximum noise levels $(L$ max $)$ was recorded in $\mathrm{Al}$ Jamhory $\mathrm{TH}$ (113.02 dBA). When taking the different location at teaching hospitals in consideration, the hospital facet of all teaching hospitals and CD was reported the highest $L_{\text {min }}$ and $L$ max noise levels; $74.85 \mathrm{dBA}$ and $111.24 \mathrm{dBA}$, respectively (Table 2 ).

Table 3 demonstrates time and day patterns of equivalent noise level of the present study. In all areas, the morning mean equivalent noise level (94.35 dBA) were significantly higher than the afternoon levels (90.14 dBA) $(p=0.037)$. Furthermore, in all areas, the mean equivalent noise level were significantly higher on the weekdays (94.05 dBA) than on the weekend $(88.57 \mathrm{dBA})(p=0.002)$. 
Table 1. Mean equivalent noise levels in the five locations of the present study in dBA with standard deviation.

\begin{tabular}{|l|c|c|c|c|c|}
\hline \multirow{2}{*}{\multicolumn{1}{c|}{ Areas }} & \multicolumn{4}{c|}{ Study settings } \\
\cline { 2 - 6 } & $\begin{array}{c}\text { Al-Jamhory TH } \\
\mathbf{n}=\mathbf{2 2}{ }^{*}\end{array}$ & $\begin{array}{c}\text { Ibn-Sena } \\
\text { General TH } \\
\mathbf{n = 2 5}\end{array}$ & $\begin{array}{c}\text { Al-Batool } \\
\text { Maternity TH } \\
\mathbf{n = 1 9}\end{array}$ & $\begin{array}{c}\text { Casualty } \\
\text { Department } \\
\mathbf{n}=\mathbf{1 4}\end{array}$ & P-value** \\
\hline \multicolumn{1}{|c|}{ Average level } & $\mathbf{9 6 . 6 6 \pm 5 . 9 1}$ & $\mathbf{8 9 . 1 6 \pm 6 . 8 3}$ & $\mathbf{9 3 . 9 0 \pm 4 . 1 7}$ & $\mathbf{9 7 . 8 0 \pm 2 . 9 1}$ & $\mathbf{0 . 0 0 1}$ \\
\hline Hospital floor & $91.84 \pm 5.53$ & $85.65 \pm 5.12$ & $90.75 \pm 5.87$ & $89.55 \pm 5.82$ & 0.063 \\
\hline Consultation unit & $94.68 \pm 6.88$ & $90.26 \pm 6.11$ & $91.22 \pm 6.01$ & ---- & 0.087 \\
\hline Intensive care units & $90.43 \pm 5.21$ & $85.46 \pm 4.81$ & ---- & --- & 0.061 \\
\hline Nurses' stations & $97.48 \pm 5.99$ & $89.48 \pm 5.93$ & $89.48 \pm 5.93$ & $99.18 \pm 5.68$ & 0.032 \\
\hline Hospital facet & $98.62 \pm 4.85$ & $92.62 \pm 4.85$ & $94.62 \pm 4.85$ & $97.82 \pm 5.67$ & 0.004 \\
\hline
\end{tabular}

* $\mathrm{n}$ : number of recording in each TH. ${ }^{* *}$ ANOVA test was used.

Table 2. The mean minimum $\left(L_{\text {min }}\right)$ and maximum $\left(L_{\text {max }}\right)$ noise levels in the study settings in dBA.

\begin{tabular}{|c|c|c|c|c|c|c|c|c|}
\hline \multirow[t]{2}{*}{ Areas } & \multicolumn{2}{|c|}{ Al-Jamhory TH } & \multicolumn{2}{|c|}{$\begin{array}{c}\text { Ibn-Sena General } \\
\text { TH }\end{array}$} & \multicolumn{2}{|c|}{$\begin{array}{c}\text { Al-Batool } \\
\text { Maternity TH }\end{array}$} & \multicolumn{2}{|c|}{$\begin{array}{c}\text { Casualty } \\
\text { Department }\end{array}$} \\
\hline & $\mathbf{L}_{\min }$ & $\mathbf{L}_{\max }$ & $\mathbf{L}_{\min }$ & $\mathbf{L}_{\max }$ & $\mathbf{L}_{\min }$ & $\mathbf{L}_{\max }$ & $L_{\min }$ & $\mathbf{L}_{\max }$ \\
\hline Average level & 73.80 & 113.02 & 71.88 & 97.12 & 75.53 & 111.44 & 74.52 & 110.20 \\
\hline Hospital floor & 72.81 & 109.89 & 71.67 & 97.65 & 74.59 & 110.07 & 74.76 & 106.26 \\
\hline Consultation unit & 72.96 & 113.89 & 72.12 & 97.89 & 75.69 & 109.13 & ---- & ---- \\
\hline Intensive care units & 70.85 & 100.11 & 68.35 & 89.22 & ---- & ---- & ---- & ---- \\
\hline Nurses' stations & 73.98 & 112.32 & 71.93 & 96.42 & 74.56 & 110.58 & 74.68 & 109.08 \\
\hline Hospital facet & 74.85 & 114.42 & 72.08 & 99.11 & 75.87 & 112.40 & 74.89 & 111.24 \\
\hline
\end{tabular}

Table 3. Time-pattern of the mean equivalent noise level in dBA for the study setting.

\begin{tabular}{|l|c|c|c|c|c|c|}
\hline \multicolumn{1}{|c|}{ Time pattern } & Al-Jamhory TH & $\begin{array}{c}\text { Ibn-Sena } \\
\text { General TH }\end{array}$ & $\begin{array}{c}\text { Al-Batool } \\
\text { Maternity TH }\end{array}$ & $\begin{array}{c}\text { Casualty } \\
\text { Department }\end{array}$ & Total & P-value* \\
\hline Morning & 97.36 & 90.16 & 94.27 & 98.84 & 94.35 & \multirow{2}{*}{0.037} \\
\hline Afternoon & 90.31 & 86.32 & 90.89 & 92.81 & 90.14 & \\
\hline Weekdays & 97.39 & 90.68 & 94.57 & 98.89 & 94.05 & \multirow{2}{*}{0.002} \\
\hline Weekend & 88.45 & 84.31 & 89.46 & 93.87 & 88.57 & \\
\hline
\end{tabular}

* Independent t-test for two means was used.

\section{DISCUSSION}

Generally speaking, a quiet hospital environment is in the range of 40 to $50 \mathrm{dBA}$, an intermediate environment would be at approximately 50 to 60 $\mathrm{dBA}$, and a noisy environment would fall in the range of 60 to $75 \mathrm{dBA}{ }^{(12)}$. The decibel scale is a linear scale that reflects logarithmic increases in sound pressures, and therefore small numerical increases represent huge differences in sound. Ambient noise at most modern hospitals fall into the 50-to-70 dBA range, with occasional eruptions well above this level. The average nighttime noise level of $67 \mathrm{dBA}$ measured in several acute care admission and general medical wards represents a large excess from the recommended level of 35 $\mathrm{dBA}^{(15)}$.
The results of this study revealed that excessive environmental noise was present in different stations in Mosul MCCTHs. The mean equivalent noise level found in this study was higher (93.44 \pm $6.55 \mathrm{dBA}$ ) than noise levels found in other health care settings ${ }^{(12,16-20)}$, where Allaochich et al. ${ }^{(16)}$ in France during 2002, did noise measurement in post anesthesia care unit of Lyon hospital and found average equivalent noise level was 67.1 dBA. Also McLaren and Maxwell-Armstrong ${ }^{(20)}$ in 2008 , found a mean Leq noise level of $73.5 \mathrm{dBA}$ in five surgical wards at Queen's Medical Center, Nottingham-UK.

Study of noise pollution in Jeddah hospitals was conducted by Noweir and Al-Jiffry ${ }^{(21)}$ on a sample of 6 hospitals during 1991; authors recorded that 
the levels of noise in clinics, patient rooms, offices, waiting areas and corridors significantly exceeded the recommended standard. Another study carried out by Juang et al. in 2007 to assess noise level in three hospitals; one regional hospital in the central part of Taiwan and two regional hospitals in the southern part of Taiwan; showed a lower figures than that of the present study $(50.3-68.1 \mathrm{dBA})^{(22)}$. In the current study the highest equivalent noise level was recorded in $\mathrm{CD}(97.80 \pm 2.91 \mathrm{dBA})$, this finding is consistent with the finding of Kracht et al. (23) in 2007, where the peak noise level during surgery in operation rooms were well in excess of $100 \mathrm{dBA}$. In the present study, the emotional outburst of the relatives of the injured and deceased and vehicular movement in that area might have contributed to the observed noise level. The lowest level of noise was observed in CCU and RCU of Ibn-Sena General TH (85.46 \pm 4.81 $\mathrm{dBA}$ ), which may be due to restricted visits of relatives. It is surprising to note that even the lowest recorded noise level was $45 \mathrm{dBA}$ higher than the recommended $\mathrm{WHO}$ level of $40 \mathrm{dBA}$ for morning hours. The WHO guidelines for noise in hospitals state that Leq levels should not exceed $35 \mathrm{dBA}$ in most rooms in which patients are being treated or observed. They also stated that, on wards, noise levels should not exceed $30 \mathrm{dBA}$ Leq (day and night) and that peak noise levels at night should not exceed $40 \mathrm{dBA}$. Such high level could slow down the recovery of patients ${ }^{(24,25)}$.

The findings of the present study in respect to $L$

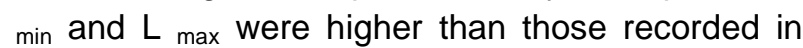
the wards of two general TH in Ibadan $63-89$ $\mathrm{dBA}$ ) in an earlier study carried out by Omokhodion and Sridhar during $2002^{(26)}$.

In the present study the average indoor noise levels of the three teaching hospitals were found to exceed the permissible limits ${ }^{(27,28)}$. Many places even in silence zones had noise levels above 75 dBA. It was alarming to note that all areas in the three teaching hospitals had levels exceeding 75 $\mathrm{dBA}$ during the morning hours. The heavy inflow of about 6000 patients every day during the morning hours could probably be one of the contributing factors for such high levels.

Noise level had certain time-pattern. Thus, in the present study, the morning (8:00, 9:00, 11:00 a.m.) noise level was significantly higher $(p=0.037)$ than the afternoon level, (94.35 Vs $90.14 \mathrm{dBA})$.
Unfortunately, the evening noise level could not be recorded due to logistic issues, difficult transportation and security circumstances which prevent the data collector from evening recording. This finding is similar to what was reported by Bharathan $\mathrm{T}$ et al. ${ }^{(29)}$ in New York Methodist Hospital during 2007, although the level was lower than the stated by the current work (68.0 Vs 58.9 dBA). In a study carried out by Vinodhkumaradithyaa et al. ${ }^{(12)}$ at Madurai-India in 2008, the mean equivalent noise level were 70.38 $\mathrm{dBA}$ in the morning and $64.46 \mathrm{dBA}$ in the evening in a tertiary care hospital.

In the present work, the level of noise was significantly higher on weekdays (94.05 dBA) than on weekends (88.57 dBA), ( $p=0.002)$. This dayby-day pattern of noise is consistent with staff activities and clinical teaching sessions during the weekdays. Quieter THs on a weekend is explained by lower number of doctors, medical staff and visitors with no teaching activities and fewer procedures performance.

\section{CONCLUSIONS}

The present work concluded that the noise pollution in Mosul MCCTHs greatly exceeded the WHO guideline level for hospitals. Time-and placepatterns of noise in Mosul Medical City Institutions followed activities of medical and non-medical staff and suggest that the noise pollution is mostly "manmade". Therefore, these results will be of help to planners and policy makers in the Nineveh Directorate of Health to combat such big problem, and there is a need for regular noise monitoring so as to establish an optimal hospital environment.

\section{REFERENCES}

1. Bluhm G, Nordling E, Bergland N. Road traffic noise and annoyance: An increasing environmental health problem. Noise Health 2004;6:43-46.

2. Persson WK, Bengtsson J, Agge A, Bjorkman M. A descriptive cross-sectional study of annoyance from low frequency noise instillations in an urban environment. Noise Health 2003:5:35-46.

3. Griefahan B. Sleep disturbances related to environmental noise. Noise Health 2002;4:57-60.

4. Joint Subcommittee on Speech Privacy. "Sound and Vibration Design Guidelines for Hospital and Healthcare Facilities". (2010) Public Draft 2.

5. Juang DF, Lee C, Yang T, Chang MC. Noise pollution and its effects on medical care workers and patients in hospitals. Environ. Sci. Tech. Autumn 2010; 7 (4): 705716. 
6. Persson WK, Bengtsson J, Kjellberg A, Benton S. Low frequency noise "pollution" interferes with performance. Noise Health 2001;4:33-49.

7. Aaron JN, Carlisle CC, Carskadon MA, et al. Environmental noise as a cause of sleep disruption in an intermediate respiratory care unit. Sleep 1996;19:70710.

8. Carley DW, Applebaum R, Banser RC, et al. Respiratory and arousal responses to acoustic stimulation. Chest 1997; 112:1567-71.

9. Barbara G. Sleep Disturbances Related to Environmental Noise. Noise \& Health 2002;4:15,57-49.

10. Xie H, Kang J, Mills GH. "Clinical review: The impact of noise on patients' sleep and the effectiveness of noise reduction strategies in intensive care units". Critical Care 2009; 13(2): 208.

11. Ising $H$, Braun $C$. Acute and chronic endocrine effect of noise: Review of the research conducted at the Institute for water, soil and air hygiene. Noise \& Health 2002;2: 7-24.

12. Vinodhkumaradithyaa A, Srinivasan $M$, Ananthalakshmi I, et al. Noise levels in a tertiary care hospital. Noise \& Health 2008;10(38):11-13.

13. Environmental Protection Agency. Information on levels of environmental noise requisite to protect public health and welfare with an adequate margin of safety. Washington, DC: Government Printing Office, 1974.

14. Guidelines for intensive care unit design. Guidelines/Practice Parameters Committee of the American College of Critical Care Medicine, Society of Critical Care Medicine. Crit Care Med 1995;23:582-8.

15. WHO, 2010. WHO Guidelines for Community Noise. $<$ :http://whqlibdoc.who.int/hq/2010>.

16. Allaouchiche $B$, Duflo $F$, Debon $R$, Bergeret $A$, Chassard D. Noise in the postanaesthesia care unit. $\mathrm{Br} J$ Anaesth 2002;88:369-73.

17. Kent WD, Tan AK, Clarke MC, Bardell T. Excessive noise levels in the neonatal ICU: Potential effects on auditory system development. J Otolaryngol 2002;31: 355-60.
18. Morrison WE, Haas EC, Shaffner DH, Garrett ES. Fackler JC. Noise, stress and annoyance in a pediatric intensive care unit. Crit Care Med 2003;31:113-9.

19. Williams AL, van Drongelen W, Lasky RE. Noise in contemporary neonatal intensive care. J Acoust Soc Am 2007;121:2681-90.

20. McLaren E, Maxwell-Armstrong C. Noise pollution on an Acute Surgical Ward. Ann R Coll Surg Engl. 2008; March;90(2):136-139.

21. Noweir MH, Al-Jiffry MS. Study of noise pollution in Jeddah hospitals. J Egypt Public Health Assoc. 1991;66(3-4):291-303. [Abstract]

22. Christensen, M. Noise levels in a general surgical ward: A descriptive study. J. Clin. Nursing, 2005;14: 156164.

23. Kracht JM, Busch-Vishniac IJ, West JE. Noise in the operating rooms of Johns Hopkins hospital. J Acoust Soc Am 2007;121:2673-80.

24. MacKenzie DJ, Galbrun L. Noise levels and noise sources in acute care hospital wards. Building Services Engg Res and Tech 2007;28:117-31.

25. Moshi AA, Philimoni K, Mkoma S. Noise Pollution on Wards in Iringa Regional Hospital, Tanzania. World Appl. Sci. J. 2010; 11 (5): 599-603.

26. Omokhodion FO, Sridhar MK. Noise levels in the hospital environment in Ibadan. Afr $\mathrm{J}$ Med Med Sci 2003;32:139-42.

27. Rampal RK, Rasool N. Assessment of noise levels in various Government Hospitals of Jammu city. J Curr Sci 2004;2:629-34.

28. Safarpour AR, Nasabi N, Mehrabi M, Hojatymanesh M, Tabatabai S. Comparison of Physical Status of Admission Wards of Shiraz Training Hospitals with Standards in 2008. World Appl. Sci. J. 2010; 8(10): 1205-1210.

29. Bharathan T, Glodan D, Ramesh A, Vardhini B, Baccash E, Kiselev P, Goldenberg G. What do patterns of noise in a teaching hospital and nursing home suggest?. Noise \& Health 2007;9:31-34. 